\title{
CRITÉRIOS PARA A (RE)UTILIZAÇÃO DOS RESÍDUOS DA INDÚSTRIA SUCROENERGÉTICA: A VINHAÇA COMO POTENCIAL FERTILIZANTE ECONOMICAMENTE VIÁVEL E ECOLOGICAMENTE SUSTENTÁVEL
}

Silvio Aparecido Silva Togneti, Edilene Mayumi Murashita Takenaka

Universidade do Oeste Paulista - UNOESTE, Mestrado em Meio Ambiente e Desenvolvimento

Regional, Presidente Prudente, SP. E-mail: edilene@unoeste.br

\section{RESUMO}

O Setor sucroenergético é uma das mais antigas atividades industriais brasileiras. Teve início com a colonização do Brasil e inicialmente era focada na produção de açúcar e aguardente. Após 1974 com o início do Proálcool, passou a se desenvolver tecnologicamente culminando com a ampliação da produção e tendo como objetivo principal a produção de etanol que seria utilizado como combustível alternativo e substituto de combustíveis derivados de petróleo. A cada ano novas tecnologias foram desenvolvidas e implantadas aumentando a eficiência industrial. Tivemos uma evolução marcante na área agrícola em termos de desenvolvimento de novos equipamentos, novas tecnologias e principalmente no desenvolvimento de novas variedades de cana de açúcar. Observa-se que o desenvolvimento do setor resultou também no desenvolvimento socioeconômico de regiões e em seu entorno ao gerar empregos diretos e indiretos. Contrariamente a isso tudo ressaltamos outro ponto que merece especial atenção: os impactos ambientais que foram potencializados com a ampliação da atividade sucroalcooleira, portanto, é mandatório que se analise quais os resíduos são produzidos pelo setor e suas destinações finais. É sob essa ótica que se desenvolverá a presente pesquisa que tem, por objetivo identificar os critérios para a re-utilização dos resíduos da indústria sucroenergética salientando o resíduo vinhaça como potencial fertilizante economicamente viável ecologicamente sustentável a partir de um programa desenvolvido por um grupo de empresas do setor e localizado no Estado de Mato Grosso do Sul. Para tanto, inicialmente, faremos uso da pesquisa bibliográfica ao buscar referencial teórico junto a obras de autores renomados da área estudada. Em um segundo momento, faremos uso da pesquisa de campo e a utilização dos dados fornecidos pela mesma, acerca do programa de destinação de vinhaça por ela desenvolvido.

Palavras-chave: Reutilização de Resíduo. Vinhaça.

\section{CRITERIA FOR ( RE ) USE OF WASTE SUGARCANE INDUSTRY: THE VINASSE AS POTENTIAL FERTILIZER ENVIRONMENTALLY SUSTAINABLE AND VIABLE ECONOMICALLY}

\begin{abstract}
The sugar-energy sector is one of the oldest Brazilian industrial activities. We began with the colonization of Brazil and was initially focused on the production of sugar and brandy. After 1974 with the start of Proalcool, it went on to develop technologically culminating with the expansion of production and having as main objective the production of ethanol would be used as an alternative fuel and petroleum fuel substitute. Every year new technologies have been developed and deployed increasing manufacturing efficiency. We had a remarkable evolution in agriculture in terms of
\end{abstract}


development of new equipment, new technologies and mainly in developing new varieties of sugar cane. It is observed that the sector's development has also resulted in the socioeconomic development of regions and its surroundings to generate direct and indirect jobs. Contrary to all this we emphasize another point that deserves special attention: the environmental impacts that have been boosted with the expansion of sugarcane activity, so it is mandatory that analyze which wastes are produced by the industry and their final destinations. It is in this light that will develop this research has the objective of identifying the criteria for re-use of waste from the sugarcane industry stressing the residue vinasse as a potential economically viable fertilizer and environmentally sustainable from a program developed by a group of sector companies and located in the State of Mato Grosso do Sul. Therefore, initially we will make use of literature to seek theoretical framework with the works of renowned authors of the study area. In a second step, we will make use of field research and the use of data provided by the same, about the vinasse allocation of program it developed.

Keywords: Reusing waste. Vinasse. 


\section{INTRODUÇÃO}

O setor sucroenergético também conhecido como setor sucroalcooleiro brasileiro compreende as atividades agrícolas e industriais relacionadas à produção de açúcar, etanol e eletricidade.

A afirmação de que o setor sucroenergético representa uma parcela importante do setor produtivo brasileiro está alicerçada em um setor com bases agrícolas e industriais concretas.

$\mathrm{Na}$ área agrícola tivemos o desenvolvimento de equipamentos que partiram de práticas rudimentares de cultivo de cana de açúcar para o que hoje conhecemos como agricultura de precisão. Novos produtos químicos foram desenvolvidos especificamente para o setor e novas variedades de cana de açúcar.

Em termos industriais, o desenvolvimento de novas tecnologias foi marcante para o setor, possibilitando o aumento da eficiência industrial e consequentemente o aumento da produção.

O aumento das áreas plantadas e o aumento da produção resultaram também em maiores volumes de resíduos industriais. Pretende-se buscar respostas às dúvidas que existem sobre a destinação correta de resíduos que, de certa forma, colocam em cheque a sustentabilidade das práticas utilizadas pelo setor. Para tanto, será dada ênfase no resíduo identificado por "vinhaça" devido ao volume gerado e também devido ao seu potencial de contaminação ambiental.

O presente projeto de pesquisa tem por objetivo verificar os critérios para a re-utilização da vinhaça como potencial fertilizante economicamente viável e ecologicamente sustentável a partir de um programa desenvolvido por um grupo de empresas do setor.

\section{METODOLOGIA}

A pesquisa bibliográfica, segundo Lakatos \& Marconi (2003), tem por finalidade posicionar o pesquisador com o que já foi anteriormente escrito sobre determinado tema, com o objetivo de permitir o esforço paralelo na análise de suas pesquisas ou manipulação de suas informações.

Assim, a metodologia que foi utilizada consistiu, primeiramente, na realização de um levantamento e aprofundamento bibliográfico sobre a temática abordada em artigos, livros, sites especializados e periódicos sobre os temas que envolvem a geração e descarte de resíduos da atividade sucroenergética e os impactos ambientais que este tipo de resíduo causa ao meio ambiente.

Sobre a Pesquisa de Campo, Lakatos e Marconi (2003) diz:

(...) utilizada com o objetivo de conseguir informações e/ou conhecimento acerca de um problema, para o qual se procura uma resposta, ou de uma hipótese que se queira comprovar, ou, ainda, descobrir novos fenômenos ou as relações entre eles.

Os relatórios sobre o programa de sustentabilidade, especificamente sobre a re-utilização da vinhaça, da empresa pesquisada foram analisados e tabulados a partir da realização de pesquisa documental.

Desta forma foi possível estabelecer comparativos entre a teoria e a prática adotada pela empresa pesquisada e atingir o objetivo do trabalho.

\section{RESULTADOS}

A empresa pesquisada faz a destinação da vinhaça de duas formas; vinhaça "in natura" ou convencional e vinhaça concentrada. 
De acordo com Freire (2000), o transporte de vinhaça "in natura" por tubulações, canais ou caminhões são viáveis tecnicamente somente em curtas distâncias. Em distâncias acima de $20 \mathrm{~km}$, as instalações de tubulações e bombeamento apresentam valores iniciais de investimentos inviáveis.

Verificamos através dos relatórios operacionais da empresa pesquisada que $96 \%$ da vinhaça "in natura" produzida passa por uma concentradora de vinhaça concentrando seu volume, os nutrientes e matérias orgânicas contidas na mesma em torno de 20 vezes.

Desta forma o transporte e aplicação através de caminhões para áreas distantes da planta industrial tornam-se viável.

Segundo Freire (2000), a vinhaça a DBO da vinhaça varia de 12.000 a 20.000 ppm, e essa agressividade ocorre por ela ter uma carga muito grande de matéria orgânica.

Em 1978 a Coopersucar elaborou um documento a título de orientação para as Usinas cooperadas sobre três formas economicamente viável de aproveitamento da vinhaça, sendo: a produção de biomassa, a utilização como fertilizante e a produção de metano.

Constatamos que toda a vinhaça concentrada produzida pela empresa pesquisada é aplicada com uso de caminhões distribuidores que aplicam a vinhaça diretamente na linha de cana em doses de reposição de nutrientes com base nos relatórios de produção de cada área cultivada.

A empresa pesquisada testou por alguns anos um sistema de produção de biogás a partir de vinhaça "in natura" e com o objetivo de aumentar a viabilidade financeira para destinação deste resíduo concentrado está instalando biodigestores para obter biogás que será utilizados como combustível na geração de energia elétrica.

Analisando as informações extraídas do fluxograma de operação de um biodigestor, a produção de energia elétrica ao final de $24 \mathrm{hs}$ de operação é de $873 \mathrm{MW}$.

Outro ponto de elevada importância a ser considerado é que o processo de biodigestão da vinhaça reduz a DQO de $275 \mathrm{~kg} / \mathrm{m}^{3}$ da vinhaça concentra para uma DQO de $83,67 \mathrm{~kg} / \mathrm{m}^{3}$ após a biodigestão.

\section{CONCLUSÃO}

A concentração da vinhaça e a sua biodigestão formam um sistema de "tratamento" desse resíduo, aumentando a viabilidade econômica por extrair gás combustível para geração de energia elétrica e principalmente por diminuir a DQO desse resíduo no Meio Ambiente, representando portanto uma prática ecologicamente sustentável.

A instalação desses dois sistemas deveria se tornar uma condicionante ambiental para que as indústrias sucroenergéticas tenham práticas sustentáveis de "tratamento e disposição de seus resíduos".

A implantação do "tratamento e disposição de seus resíduos" pode ser viabilizada através de incentivos do BNDES e do Banco Mundial.

Concluímos que o modelo de sistema Concentração e Biodigestão de vinhaça concentrada, se aplica perfeitamente na região do Mato Grosso do Sul onde a empresa pesquisada está implantada, e que se for adotado na região de Presidente Prudente, a viabilidade será ainda maior, face às distâncias das fazendas na região do Pontal do Paranapanema serem maiores que as do Mato Grosso do Sul e também devido à carência de nutrientes do solo dessa região ser maior.

Desta forma o desenvolvimento regional de Presidente Prudente seria alavancado com a maior utilização da agricultura de precisão, ganho na produção de energia explorando a mesma área plantada e geração de novos empregos. 


\section{REFERÊNCIAS}

CO JUNIOR, C.; MARQUES, M. O.; TASSO JUNIOR, L. C. Efeito residual de quatro aplicações anuais de lodo de esgoto e vinhaça na qualidade tecnológica da cana-de-açúcar. Eng. Agríc., Jaboticabal , v. 28, n. 1, p. 196-203, Mar. $2008 \quad$ Disponível em: http://www.scielo.br/scielo.php?script=sci arttext\&pid=S0100-

69162008000100020\&Ing=en\&nrm=iso > Acesso em: 10/07/2014.

GIL, A. C. Métodos e técnicas de pesquisa social. 5.ed. São Paulo: Atlas, 2003

LAKATOS, E. M., Fundamentos da Metodologia Científica. 5 ed, São Paulo: Atlas, 2003

ORLANDO FILHO, J. (coord). Nutrição e adubação da cana-de-açúcar no Brasil. Piracicaba, IAA/PLANALSUCAR, 1983

REZENDE, G. C.; GOLDIN, I. A agricultura brasileira na década de 80: crescimento numa economia em crise. Rio de Janeiro: IPEA, 1993.

ROSSETO, R. A. Cana de açúcar e a questão ambiental. In: MIRANDA, L. L. D. ; VASCONVELOS, A. C. M.; LANDELL, M. D. A. Cana de açúcar. Campinas: Instituto Agronômico, 2008

SANTIAGO, A. D.; ROSSETTO, R. Árvore do conhecimento.(s.d.)

<Disponível em: http://www.agencia.cnptia.embrapa.br/gestor/cana-deacucar/arvore/CONTAG01 141 22122006154842.html> Acesso em 10/08/2015.

SCANDIFFIO, M. I. G. Análise Prospectiva do Álcool Combustível no Brasil-Cenários 2004-2024. (tese de Doutoramento) Universidade Estadual de Campinas, Faculdade de Engenharia Mecânica, 2005.

MENDES, J.T.Grassi. Agronegócio: uma abordagem econômica - São Paulo: Pearson Prentice Hall, 2007.

OLIVEIRA, Djalma de P.R. Planejamento estratégico: conceitos, metodologias e

Prapráticas.14.ed. São Paulo: Atlas, 1999.

EIGENHEER, E.M..A limpeza Urbana através dos tempos. -Porto Alegre RS: Pallotti 2009

PRADO, R.M. Nutrição de Plantas- São Paulo: Editora Unesp, 2008

FREIRE, W. J.: Vinhaça de cana de açúcar- Guaíba: Agropecuária, 2000

MALAVOLTA et al, E. Avaliação do estado nutricional das plantas: princípios e aplicações - 2.ed Piracicaba: potafos, 1997

SEGATO et al, S.V. Atualização em produção de cana de açúcar - Piracicaba: CP2, 2006

Pereira Neto, J. T. Manual de compostagem: processo de baixo custo -Viçosa, MG: Ed. UFV, 2007 
Fundação Estadual do Meio Ambiente. Guia técnico ambiental de biogás na agroindústria. Federação das Indústrias do Estado de Minas Gerais, Cooperação Alemã para o Desenvolvimento Sustentável (GIZ). --- [Belo Horizonte]:2015

https://pt.wikipedia.org/wiki/Demanda_qu\%C3\%ADmica_de_oxig\%C3\%AAnio 